American Journal of Pharmacology and Toxicology 5 (1): 34-41, 2010

ISSN 1557-4962

(C) 2010 Science Publications

\title{
Taurine Implicated in Bromocriptine Induced Hallucination: Glycine-Glutamic-Aspartic Implicated in Bromocriptine Induced Schizophrenia
}

\author{
Abdulrahim Abu Jayyab \\ Department of Pharmacology and Toxicology, \\ College of Pharmacy and Health Sciences, \\ Ajman University of Science and Technology, Fujairah Campus, \\ P.O. Box 2202, Al-Fujairah, UAE
}

\begin{abstract}
Problem statement: The literature is reviewed and supports a strong anecdotal relationship between bromocriptine use and psychosis. It is well known that any interference with brain amino acid levels is likely to lead to disorder. Our previous research has shown that bromocriptine produced significant changes in the heart and kidneys amino acid contents. It has been confirmed that the brain amino acids concentrations are influenced by plasma amino acid levels. Therefore, it is the thought of interest to investigate the effect of bromocriptine, sulpiride or their combination on the brain and plasma amino acid concentrations of rat. Approach: The influence of chronic treatment with bromocriptine $20 \mathrm{mg} \mathrm{kg} \mathrm{day}^{-1}$ i.p, sulpiride $20 \mathrm{mg} \mathrm{kg} \mathrm{day}^{-1}$ i.p. or their combination bromocriptine $20 \mathrm{mg} \mathrm{kg} \mathrm{day}{ }^{-1}$ i.p + sulpiride $20 \mathrm{mg} \mathrm{kg} \mathrm{day}^{-1}$ i.p. for 6 weeks on free amino acids in the brain and the plasma of rats were carried out. The amino acids were quantified using the LKB 4400 Amino Acid Analyzer and the Hamilton's amino acid calibration standards. Results: Bromocriptine significantly decreased the plasma content of glutamic acid, glycine and alanine. $(\mathrm{p}<0.05, \mathrm{n}=7)$. Sulpiride did not affect basal or bromocriptine-induced changes in the plasma amino acid concentrations. Also, results indicate that bromocriptine decreased the brain content of taurine, glycine and aspartic acid. The mean $\%$ decreases were $40 \pm 3,55 \pm 6$ and $30 \pm 4$ respectively $(\mathrm{p}<0.01, \mathrm{n}=7)$. Sulpiride prevented the decreases in glycine and aspartic acid only. Conclusion: This study provided evidence for the possible involvement of some amino acids in mediating some actions of bromocriptine. Our previous results presented evidence for the antagonistic effect of taurine on some bromocriptine-induced actions that probably involve activation of 5-HT receptors. As a result, bromocriptine-induced depletion of brain taurine, which involved activation seretonergic receptors, may underlie the appearance of some side effects of bromocriptine such as hallucinations in Parkinson's patients. Thus, bromocriptine induced hallucination is related to non dopaminergic action. Further, the results direct the attention to the possible involvement of glycine, aspartic and glutamic in bromocriptine induced schizophrenia. This study indicates that different mechanisms of the etiology of schizophrenia which are not possible based upon dopaminergic mechanism alone.
\end{abstract}

Key words: Bromocriptine, sulpiride, amino acids, brain, plasma, taurine, hallucinations, glycine, glutamate, aspartic, schizophrenia

\section{INTRODUCTION}

Bromocriptine (2-bromo-a-ergocriptine) is an ergot polypeptide derivative that combines with dopamine receptors in various tissues (Johnson et al., 1976). Dopamine agonist drugs are the treatment of choice for most patients with hyperprolactinemia (Ho and Thorner, 1988; Crosignani and Ferrari, 1990). Bromocriptine has been the reference compound and effectively suppresses prolactin secretion, restores gonadal function and shrinks prolactinomas (Vance et al., 1984). Sulpiride is an antipsychotic drug that acts as a selective blocking agent of pre-and post dopamine receptors (Alander et al., 1980). Bromocriptine is believed to decrease plasma prolactin levels by activating central dopaminergic receptors in various mammals (Brooks and Welsch, 1974). A single injection of the compound into rats induced a decrease in plasma prolactin levels that lasted several days, albeit it's short half-life in the plasma (Brooks and Welsch, 1974). This has been attributed to 
the accumulation of the compound in the pituitary (Thorner et al., 1980). It is possible that the compound may have affected the synthesis and/or release of some stable endogenous compounds. Likely, candidates are the brain amino acids. This assumption is based on the knowledge that both taurine and glycine stimulate prolactin release in rats (Scheibel et al., 1980; Banzan and Donoso, 1983). Also, its current uses include the treatment of Parkinson's disease, postpartum ablation, prolactionmas, acromegaly and amenorrhea and galactorrhea secondary to neuroleptic use (Abu-Jayyab, 1991). It has often been reported to produce psychiatric side effects such as confusion, hallucinations and delusions (Boyd, 1995). The literature is reviewed and supports a strong anecdotal relationship between bromocriptine use and psychosis (Boyd, 1995). It is well known that any interference with brain amino acid levels is likely to lead to psychiatric disorder (Bruinvels and Pepplinkhuizen, 1984; Altamura et al., 1995; Levine et al., 2000; Buchanan et al., 2007). Our previous research has shown that bromocriptine produced significantly changes in the heart and kidneys amino acid contents (Ageel et al., 1987). It has been confirmed that the brain amino acids concentrations are influenced by plasma amino acid levels (Cotman et al., 1987; Voog and Eriksson, 1992). Therefore, it is thought of interest to investigate the effect of bromocriptine, sulpiride or their combination on the brain and plasma amino acid concentrations of rat.

\section{MATERIALS AND METHODS}

Animals: Male Sprague-Dawley rats weighing from 170$200 \mathrm{~g}$, were selected in this study. The rats were housed in groups (three or four in standard polypropylene cage) and maintained under standard laboratory conditions at an ambient temperature of $23 \pm 2^{\circ} \mathrm{C}$, relative humidity $50 \pm 15 \%$ and normal photo period $(12 \mathrm{~h}$ dark $/ 12 \mathrm{~h}$ light). Commercial pellet diet (manufactured by Grani Siols and Flour Mills Organization Feed Mill) and water were provided ad libitum.

Treatment of the animals: Rats were randomly divided into 4 groups, each consisting of 7 animals. All animals were injected I.P. daily for 6 weeks as follows: group 1, received bromocriptine mesylate $20 \mathrm{mg} \mathrm{kg}^{-1}$, group 2, received sulpiride $10 \mathrm{mg} \mathrm{kg}$; group 3 , received bromocriptine mesylate $20 \mathrm{mg} \mathrm{kg}^{-1}+$ sulpiride $20 \mathrm{mg} \mathrm{kg}^{-1}$ and group 4: (Control group), received a saline solution (vehicle). Drugs were dissolved in pyrogen-free Distilled water. A few drops of diluted HCI were used to enhance the solubility of sulpiridc. Prior to drugs administration the body weights of the rats were determined and appropriate dose of each drug per $\mathrm{kg}$ was then added.

Preparation of the brain tissues for amino acids analysis: To prepare tissue homogenates for free amino acid determination, after treatments, animals in the various groups $(n=7)$ were anaesthetized with ether, the" thorax was opened rats were stunned and decapitated the thorax and abdomen were immediately opened. The skulls were quickly opened and the whole brains removed. Each organ was quickly excised and washed in ice-cold Krebs buffer to remove any traces of blood. Brain tissues were blotted dry on (Whatman) filter paper and weighed. To each sample $5 \mathrm{~mL}$ of $0.9 \%$ saline ere added and tissues homogenized for 30$120 \mathrm{sec}$. (HY-Homogenizer, FRG). Homogenates were then centrifuged at 10,000 rpm (MSE Centrifuge)) for $20 \mathrm{~min}$ at $4^{\circ} \mathrm{C}$. The total volume of each supernatant was noted and $1 \mathrm{~mL}$ was removed from each sample and placed in centrifuge tubes. To each sample, $50 \mathrm{mg}$ of 5'-sulphosalicylic acid were added, mixed and incubated in the cold room at $4^{\circ} \mathrm{C}$ for $1 \mathrm{~h}$. The $\mathrm{PH}$ adjusted samples were further centrifuged at $15,000 \mathrm{rpm}$ in an ultra centrifuge (Epperdorf, Gateau, 5414), for $20 \mathrm{~min}$. in the cold room. The supernatant fractions were then removed and adjusted to $\mathrm{PH} 2.2$ with $\mathrm{LiOH}$ solution (buffer F). The final volume was adjusted for $1 / 2$ dilution. The final results for amino acids were multiplied by 2 to account for the dilution factor. About $40 \mu \mathrm{L}$ aliquots of the samples were injected into the capsules and loaded on the LKB 4400 Amino Acid Analyzer (Biochrom Ltd., Cambridge, England). The concentrations of the free amino acids recorded on chromatograms were calculated with a LKB 2220 integrator. The concentrations of amino acids in the brain tissue were expressed as umol/100 g wet tissue (Block et al., 1966).

Collection and preparation of the plasma for amino acid determinations: At the end of the 6 weeks experimental period, other groups of animals were anaesthetized with ether and $5 \mathrm{~mL}$ blood were drawn by cardiac puncture, via a $10 \mathrm{~mL}$ plastic syringe and transferred to EDTA Vacutainer tubes. The blood was then mixed with EDTA-anticoagulant in the tubes and centrifuged at $1000 \times \mathrm{g}$ for $5 \mathrm{~min}$. The plasma was immediately separated and the free amino acids were determined (Block et al., 1966) after deproteinization of plasma. Processing the plasma samples required adding $1 \mathrm{~mL}$ plasma to a bullet centrifuge tube containing $50 \mathrm{mg} 5$ ' sulphosalicylic acid, this was then vortex mixed thoroughly, incubated at $4^{\circ} \mathrm{C}$ for $60 \mathrm{~min}$, then spun at $10000 \times \mathrm{g}\left(\right.$ MSE Centrifuge) at $4^{\circ} \mathrm{C}$ for $20 \mathrm{~min}$. A $200 \mu \mathrm{L}$ aliquot was $\mathrm{PH}$ adjusted to 2.2 using 
LiOH (buffer F). Usually, $100 \mu \mathrm{L}$ of buffer $\mathrm{F}$ is sufficient. The final volume was then adjusted to give a 1:2 dilution by adding a further $100 \mu \mathrm{L}$ of loading buffer to the supernatant. Finally, $40 \mu \mathrm{L}$ of PH adjusted sample was injected into the capsule, which delivered that sample into the amino acid analyzer system; in this case the LKB 4400 amino acid analyzer (Biochrom Ltd., Cambridge, England). Connected with a LKB 2220 integrator. The free amino acids were quantitated using standard amino acids as detailed in the LKB manual. The concentrations of amino acids in plasma were expressed as nmol $\mathrm{mL}^{-1}$.

The analytical column: The chromatographic column used was made of stainless steel $(200 \times 4.6 \mathrm{~mm})$ packed with cation exchange u1tropac-8 Resin, Lithium form. (Sulfonated polystyrene Resin, No. L320, 8+0.5 um, known as the Golden Column (LKB).

Elution of the amino acids: The free amino acids were eluted using five Lithium citrate buffers in series as described in the LKB Manual. These were buffer A 0.2 M. pH 2.8; buffer B 0.3 M. pH 3; buffer C $0.6 \mathrm{M}$. $\mathrm{pH} 3.02$; buffer D 1.0 M, pH 3.45 and buffer E 1.6 M. $\mathrm{pH}$ 3.3. After chromatography of each sample, the column was automatically regenerated with $0.3 \mathrm{M} \mathrm{Li}$ $\mathrm{OH} \mathrm{pH} 3.3$. The time required to elute all amino acids and other ninhydrin positive compounds in each sample was $140 \mathrm{~min}$.

Parameters of analysis: Flow rates for buffers and ninhydrin were 25 and $45 \mathrm{~mL} \mathrm{~h}^{-1}$ respectively. The pressures used were 38 for the buffers. About 49 for ninhydrin and 6 bars for the reaction coil. Column temperatures were $\mathrm{T} 1=34$. $\mathrm{T} 2=61$ and $\mathrm{T} 3=75$. Chart speed was120 $\mathrm{nm} \mathrm{h}^{-1}$.

Retention time reproducibility: In order to assess the retention time reproducibility of the analysis procedure a series of amino acids calibration standards were separated and retention times for each amino acids separated was measured using an LKB 4440 Ultra data system. The mean \pm SEM retention time for each amino acids were calculated and the percentage variation in retention times were also calculated.

Efficiency of the extraction procedure: To assess the efficiency of the extraction procedure used in this study, known quantities of standard amino acids $(n=3)$ were exposed to the same extraction procedure to which the tissues were exposed. The obtained peaks were then compared with the peaks obtained from untreated amino acids standards. The percentage of efficiency of the extraction procedure for each amino acid was then calculated.
Statistical analysis: All the data were subjected to statistical analysis using student's t-test for non-paired samples and comparative values were considered statistically significant for p-values $<0.05$ (Sokal and Rholf, 1981).

\section{RESULTS}

Reproducibility of the retention times for the amino acids: The retention times mean $\pm \operatorname{SEM}(n=7)$ for the major of the free amino acids analyzed are shown in Table 1. The percentage variation ranged from $\pm 0.1 \%$ for taurine and GABA to $\pm 0.8 \%$ for aspartic acid.

The amino acids which were detected by LKB 4400 Amino Acid Analyzer using the Gold Colum.

Percentage recovery of the free amino acids: Analysis of known concentrations of standard Amino acids exposed to the same extraction procedure as the tissues showed that the percentage recovery for the various amino acids a ranged from $97.5 \pm 1.0$ for glycine to $99 \pm 1$ taurinc, other amino acids were within this range.

Table 1: List of amino acids and retention times of physiological calibration standards (Hamilton-type P-AN and P-B) used with LKB 4400 amino acid analyzer

\begin{tabular}{lr}
\hline Amino Acid & Retention time \\
\hline Taurine & $7.39 \pm 0.65$ \\
Phosphethanolamine & $8.38 \pm 0.80$ \\
Urea & $10.34 \pm 0.34$ \\
Aspartate & $17.19 \pm 1.04$ \\
Threonine & $23.42 \pm 0.76$ \\
Serine & $25.29 \pm 0.67$ \\
Glutamate & $29.02 \pm 1.23$ \\
Glutamine & $31.82 \pm 1.03$ \\
Sarcosine & $35.90 \pm 1.15$ \\
$\alpha$-Amino Adipate & $39.42 \pm 0.82$ \\
Proline & $41.46 \pm 0.82$ \\
Glycine & $43.37 \pm 0.43$ \\
Alanine & $44.72 \pm 0.69$ \\
Homocystine & $47.47 \pm 0.78$ \\
Valine & $49.86 \pm 1.09$ \\
Cystine & $52.56 \pm 0.65$ \\
Methionine & $57.10 \pm 1.09$ \\
Cystathionine & $59.29 \pm 0.43$ \\
Isoleucine & $61.91 \pm 1.09$ \\
Leucine & $64.71 \pm 1.32$ \\
Tyrosine & $72.12 \pm 1.60$ \\
Phenylalanine & $75.57 \pm 0.76$ \\
B-Amino Isobutyrate & $77.84 \pm 1.87$ \\
Ethanolamine & $86.99 \pm 1.09$ \\
Ammonia & $89.59 \pm 1.78$ \\
Ornithine & $98.68 \pm 1.32$ \\
Lysine & $102.69 \pm 1.98$ \\
1-methyl Histidine & $105.37 \pm 156$ \\
Histidine & $106.88 \pm 0.45$ \\
3-methyl Histidine & $111.49 \pm 1.90$ \\
Anserine & $114.91 \pm 0.76$ \\
Carnosine & $119.10 \pm 1.45$ \\
Arginine & $126.34 \pm 1.87$ \\
\hline Means \pm SEM, $\mathrm{n}=7$ & \\
&
\end{tabular}


Am. J. Pharm. \& Toxicol., 5 (1): 34-41, 2010

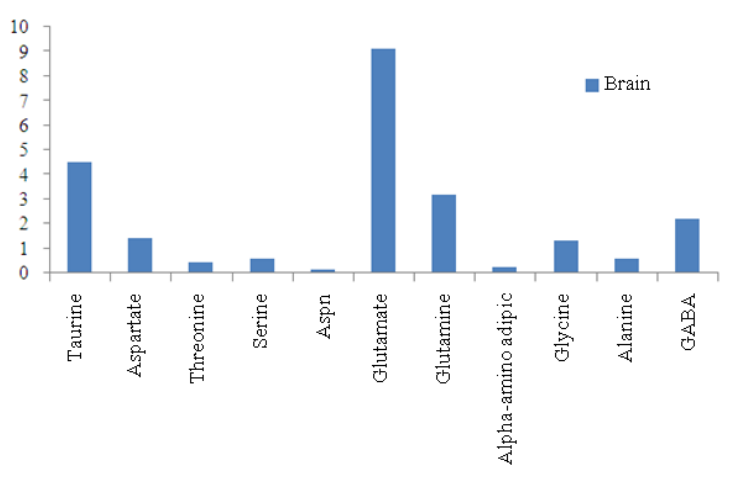

Fig. 1: Free amino acid levels in the brain and plasma of the rats; (Values are mean \pm SEM, $\mathrm{n}=7$ ); (nmoles $\mathrm{mL}^{-1}$ wet tissue)

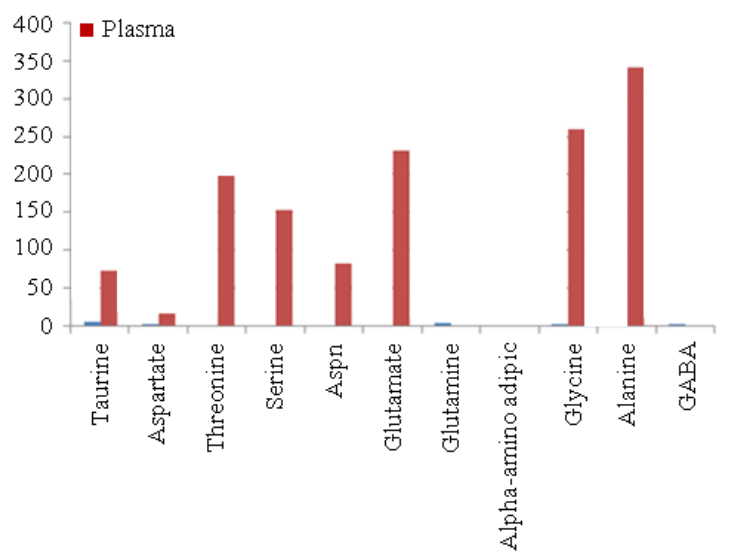

Fig. 2: Free amino acid levels in the brain and plasma of the rats; (Values are mean \pm SEM, $n=7$ ); $\left(\mu \mathrm{mol} \mathrm{g}{ }^{-1}\right.$ wet tissue)

Table 2: Free amino acid levels in the brain and plasma of the rats

\begin{tabular}{lll}
\hline Amino Acid & Brain & Plasma \\
\hline Taurine & $4.40 \pm 0.23$ & $72 \pm 8$ \\
Aspartate & $1.42 \pm 0.08$ & $16 \pm 1$ \\
Threonine & $0.45 \pm 0.05$ & $198 \pm 21$ \\
Serine & $0.58 \pm 0.03$ & $153 \pm 21$ \\
Aspn & $0.14 \pm 0.01$ & $82 \pm 8$ \\
Glutamate & $9.10 \pm 0.73$ & $242 \pm 22$ \\
Glutamine & $3.21 \pm 0.1$ & Not detected \\
Alpha-amino adipic & $0.25 \pm 0.02$ & Not detected \\
Glycine & $1.33 \pm 0.10$ & $260 \pm 11$ \\
Alanine & $0.61 \pm 0.03$ & $341 \pm 13$ \\
GABA & $2.19 \pm 0.10$ & Not detected \\
\hline
\end{tabular}

(Values are mean \pm SEM, $\mathrm{n}=7$ ); ( $\mu$ mol $\mathrm{g}$ wet tissue for brain and $\mathrm{nmol} \mathrm{mL}^{-1}$ in plasma)

Table 3: Effect of Bromocriptine (B) and Sulpiride (S) on some free amino acid content of the brain of rats

\begin{tabular}{lllll}
\hline Amino Acid & $\mathrm{C}$ & $\mathrm{B}$ & $\mathrm{B}+\mathrm{S}$ & $\mathrm{S}$ \\
\hline Taurine & $4.40 \pm 0.23$ & $2.69 \pm 0.12^{*}$ & $2.58 \pm 0.29^{*}$ & $3.23 \pm 0.39$ \\
Aspartate & $1.42 \pm 0.08$ & $0.99 \pm 0.04^{*}$ & $1.47 \pm 0.08$ & $1.28 \pm 0.03$ \\
Glycine & $1.33 \pm 0.10$ & $0.59 \pm 0.04^{*}$ & $0.96 \pm 17$ & $1.20 \pm 0.10$ \\
\hline *: $\mathrm{p}<0.05, \mathrm{n}=7$ (compared with control); $(\mu$ mol g wet tissue, Values \\
are mean $\pm \mathrm{SEM}, \mathrm{n}=7$ )
\end{tabular}

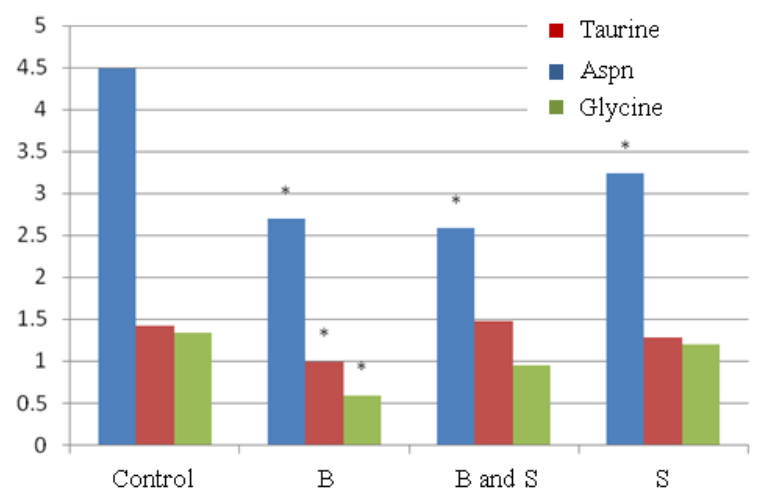

Fig. 3: Effect of Bromocriptine (B) and Sulpiride (S) on some free amino acid content of the brain of rats; $(\mu \mathrm{mol} \mathrm{g}$ wet tissue, Values are mean \pm SEM, $\mathrm{n}=7$ )

Free amino acids in the brain and plasma of the rats: The principal amino acids detected in the brain and plasma of the rats are shown in Fig. 1 and 2 and in Table 2. The amino acids of the highest concentrations in the brain were taurine, glutamic acid, glutamine, glycine and alanine. The brain also contained a high concentration of GABA and aspartic acid. The major amino acids detected in the plasma were glutamic acid, glycine, alanine and threonine (Table 2). Of the nonamino acids ninhydrin positive compounds the brain contained relatively high concentrations of phosphoethanolamine, $2.35 \pm 0.19 \mu \mathrm{mol} \mathrm{g}^{-1}$ wet tissue.

Effect of bromocriptine and sulpiride on the free amino acids:

Effect on the brain: Bromocriptine significantly decreased the brain content of taurine, glycine and aspartic acid (Table 3 and Fig. 3). The mean \% decreases were $40 \pm 3,55 \pm 6$ and $30 \pm 4$ respectively $(\mathrm{p}<0.01, \mathrm{n}=7)$. Sulpiride did not affect brain amino acid contents but significantly abolished the inhibitory effect of bromocriptine on glycine and aspartic acid without affecting the bromocriptine induced decrease in taurine.

Effect on plasma: Table 4 and Fig. 4 show the effect of bromocriptine and sulpiride on plasma free amino acids. Bromocriptine significantly decreased the plasma content of glutamic acid, glycine and alanine $\left(p^{*}<0.05, n=7\right)$. Sulpiride did not affect basal or bromocriptine-induced changes in the plasma free amino acids. 


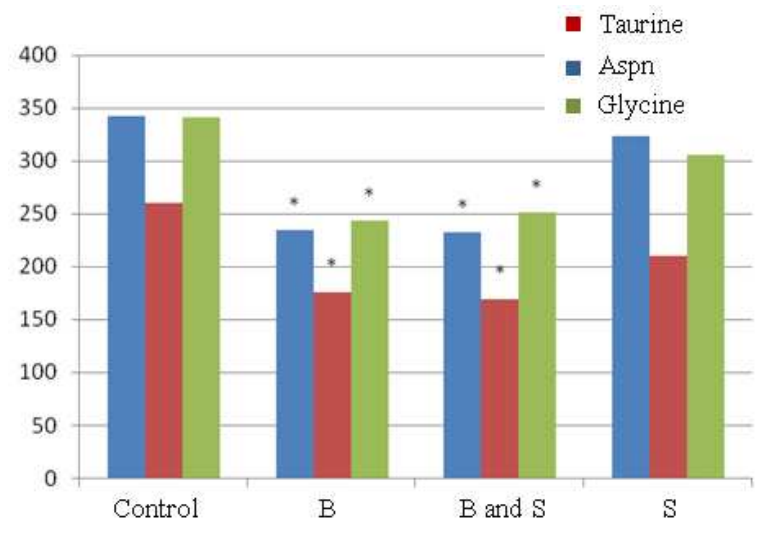

Fig. 4: Effect of Bromocriptine (B) and Sulpiride (S) on some free amino acid levels in the plasma of rats; $\left(\mathrm{nmol} \mathrm{mL}^{-1}\right.$ Values are mean $\pm \mathrm{SEM}, \mathrm{n}=7$ )

Table 4: Effect of Bromocriptine (B) and Sulpiride (S) on some free amino acid levels in the plasma of rats

\begin{tabular}{lllll}
\hline Amino acid & $\mathrm{C}$ & $\mathrm{B}$ & $\mathrm{B}+\mathrm{S}$ & $\mathrm{S}$ \\
\hline Glutamic & $342 \pm 22$ & $2.34 \pm 17^{*}$ & $232 \pm 12^{*}$ & $323 \pm 25$ \\
Glycine & $260 \pm 11$ & $176.00 \pm 10^{*}$ & $169 \pm 14^{*}$ & $210 \pm 10$ \\
Alanine & $341 \pm 13$ & $243.00 \pm 11^{*}$ & $251 \pm 19^{*}$ & $306 \pm 17$ \\
\hline$*: \mathrm{p}<0.05, \mathrm{n}=7$ (compared with control); & $\left(\right.$ ńmol $\mathrm{mL}^{-1}$ Values are \\
mean + SEM $\mathrm{n}=7$ ) & & &
\end{tabular}

\section{DISCUSSION}

This investigation revealed that some amino acids of the brain and plasma respond markedly to chronic administration of bromocriptine. Really, several mechanisms exist for the transport of amino acids across cell membranes. The Gamma glut amyl cycle is one example for the group transfer mechanism of amino acid transport. Such transport may result from activation of the enzyme Gamma Glutamyl Transpeptidase $(\gamma \mathrm{GT})$ and glutathione both of which are present in the examined organs, which are implicated in amino acid transport across cell membranes (Meister, 1973). The decrease in brain amino acids induced by bromocriptine may result from: (a) an increased utilization of amino acids as energy source, (b) a decrease in the biosynthesis and/or activity of some enzymes involved in the amino acids biosynthesis. This may result from a decrease in brain oxidative metabolism as a consequence of bromocriptine-induced hypothermia (Calne et al., 1975), (c) an increase in brain cell permeability resulting in loss of some amino acids that are normally maintained within the cells.

Both taurine (Scheibel et al., 1980) and glycine (Banzan and Donoso, 1983) are known to stimulate prolactin release in rats. Thus, it would be reasonable to suggest that bromocriptine-induced depletion of brain taurine and glycine may contribute to the inhibitory effect of the compound on prolactin release.

The amino acids induced changes in the brainwith the exception of taurine seemed to involve activation of dopamine $D_{2}$ receptors since they were prevented by the dopamine $\mathrm{D}_{2}$ receptors antagonist, sulpiride (Creese et al., 1984). The effectiveness of bromocriptine on the concentration of taurine in the brain suggested the involvement of non-dopaminergic receptors, probably 5-HT receptors. This suggestion supported by the finding that bromocriptine is known to activate 5-HT receptors (Maj et al., 1977). Support for this assumption comes from our previous finding that bromocriptine, albeit in a relatively high concentration, stimulated the rabbit jejunum and the rat uterus via activation of 5-HT receptors (Abu-Jayyab, 2007). Both effects were abolished by cyproheptadine and taurine (Abu-Jayyab, 2007). Bromocriptine-induced reduction in the brain taurine may underlie the appearance of some side effects of bromocriptine such as hallucinations in Parkinson's patients. Indeed, it was reported that taurine is a putative inhibitory synaptic transmitter, deficiency of brain taurine may possibly have caused the psychiatric and neurological manifestations of Hereditary mental depression and Parkinsonism (Perry et al., 1975). Further, it was reported that taurine improves impaired memory in animals (Vohra and Hui, 2000) and treats seizureassociated brain damage (El Idrissi et al., 2003). It seems likely that bromocriptine induced hallucination is related to non dopaminergic action.

According to neurobiochemical theories, high dopamine level in the brain is the main factor of the etiology of schizophrenia. The main support for the theory that too much dopamine causes schizophrenia is the fact that antipsychotic medications, which are used to treat schizophrenia, block dopamine receptors (DeLisi, 2008). Those treated with dopamine enhancing such as bromocriptine and levodopa for Parkinson's disease can experience psychotic side effects mimicking the symptoms of schizophrenia, particularly after large doses or prolonged use (Lieberman et al., 1987; Curran et al., 2004).

Our current results indicated that bromocriptine induced depletion of brain glycine. This effect is involved activation of dopamine $\mathrm{D}_{2}$ receptors since they were prevented by the dopamine $\mathrm{D}_{2}$ receptors antagonist, sulpiride (Creese et al., 1984). This action on glycine may contribute to the symptoms of schizophrenia. Support for this suggestion comes from the finding that glycine suggested as modulators in schizophrenia (Javitt, 2002) N-Methyl-D-Aspartate (NMDA) receptor dysfunction may play a key role in 
the pathophysiology of schizophrenia, NMDA receptorcoupled glycine receptors in the pathogenesis of schizophrenia (Millan, 2002). Indeed, it was reported that glycine is an essential cofactor for NMDA receptors; without it, the receptor does not work properly (Coyle and Tsai, 2004). Glycine treatment added to a standard regimen of antipsychotics could have substantial benefits in refractory schizophrenics (Costa et al., 1990).

On the other side bromocriptine significantly decreased the plasma level of glutamic acid, glycine and alanine. It is documented that dysfunction of glutamatergic neurotransmission implicated in the pathophysiology of schizophrenia, especially of the negative symptoms (Goff and Coyle, 2001). In schizophrenia, many glutamate-regulated processes seem to be perturbed (Konradi and Heckers, 2003). There is evidence of implicating abnormal glutamatergic neurotransmission in schizophrenia and mood disorders (Arun et al., 2008). Alterations in NAAG metabolism have been implicated in the development of schizophrenia via dysregulation of glutamate neurotransmission (Nowak et al., 1984). Indeed, glutamate and aspartic metabolites, NAcetylaspartate (NAA) and N-Acetylaspartylglutamate (NAAG) are important in the regulation of interactions of brain cells and in the establishment and maintenance of the nervous system (Baslow, 2000).

In the last years, considerable attention has been given to the NMDA receptor ion channel complex because of its unusual properties and role in brain physiology. This complex allows $\mathrm{Ca}^{2+}$ influx into the neurons only when the membrane is depolarized and the receptors bind both glutamate and glycine (Nowak et al., 1984; Johnson and Ascher, 1987; Kleckner and Dingledine, 1988). Published data revealed that the pharmacological binding specificity of L-glutamate and L-aspartic acid and indicated an interaction with different NMDA-type receptors (Di Giovanni et al., 2010). Moreover, it was found that Dalanine is another endogenous agonist of the NMDAglycine site that might have beneficial effects on schizophrenia, the significant improvement with the Dalanine further supports the hypothesis of hypofunction of NMDA neurotransmission in schizophrenia and strengthens the proof of the principle that NMDAenhancing treatment (Tsai et al., 2006). Recently it is glycine site that is the focus of many proposed therapies to potentiate NMDA receptor activity in the brains of people with schizophrenia (Shim et al., 2008).

However, further scientific observations have revealed that the Dopamine hypothesis is not a complete etiological explanation for schizophrenia.
Increased dopamine is associated with positive symptoms but not all people with schizophrenia experience the psychotic symptoms (Johnson and Ascher, 1987). Many research has suggested that other neurotransmitters and other brain areas are implicated in schizophrenia (Maguire, 2002). These results give new evidence that depletion of glycine, glutamic and aspartic might involve dopaminergic agonists induced schizophrenia and may help explain some of the negative and cognitive symptoms of schizophrenia.

\section{CONCLUSION}

This study provides evidence for the possible involvement of some amino acids in mediating some actions of bromocriptine. Our previous results presented evidence for the antagonistic effect of taurine on some bromocriptine-induced actions that probably involve activation of 5-HT receptors. As a result, bromocriptine-induced depletion of brain taurine, which involved activation seretonergic receptors, may underlie the appearance of some side effects of bromocriptine such as hallucinations in Parkinson's patients. Thus, bromocriptine induced hallucination is related to non dopaminergic action. Further, the results direct the attention to the possible involvement of glycine, aspartic and glutamic in bromocriptine induced schizophrenia. This study indicates that different mechanisms of the etiology of schizophrenia which are not possible based upon dopaminergic mechanism alone

Both, taurine and glycine are known to stimulate prolactin release in rats. Thus, it would also be reasonable to suggest that bromocriptine-induced depletion of brain taurine and glycine may contribute to the inhibitory effect of the compound on prolactin release.

Recommendations: On broad basis, these results may lead to new conceptualizations and some potential clinical approaches of hallucination and schizophrenia. It would be reasonable to suggest co-administration of taurine with bromocriptine to suppress the hallucinations that accompany consumption of high doses of bromocriptine by Parkinson's disease patients, where given glycine with bromocriptine to avoid bromocriptine induced schizophrenia in Parkinson's disease patients or other clinical uses of bromocriptine. Co-administration of both taurine and glycine would combat (oppose) bromocriptine induced side effects at high doses. 


\section{REFERENCES}

Abu-Jayyab, A.R., 1991. Insights on the mechanism of action of bromocriptine. J. Pharm. Med., 1: 185-194.

Abu-Jayyab, A., 2007. Antagonism between taurine and bromocriptine in rat uterus in vitro and in vivo. UOS J. Pure Applied Sci., 4: 63-76.

Ageel, A.M., K.E.H. El-Tahir and A.R. Abu-Jayyab, 1987. The influence of bromocriptine on free amino acids in the kidneys and heart of the rat. Biochem. Pharmacol., 36: 4293-4295. PMID: 3689453

Boyd, A., 1995. Bromocriptine and psychosis: A literature review. Psychiat. Q., 66: 87-95. DOI: 10.1007/BF02238717

Alander, T., N.E. Anden and M. Grabowska-Anden, 1980. Metoclopramide and sulpiride as selective blocking agents of pre-and postsynaptic dopamine receptors. Naunyn-Schmiedeberg's Arch. Pharmacol., 312: 145-150. PMID: 7402361

Altamura, C., M. Maes, J. Dai and H.Y. Meltzer, 1995. Plasma concentrations of excitatory amino acids, serine, glycine, taurine and histidine in major depression. Eur. Neuropsychopharmacol., 5: 71-75. PMID: 8775762

Arun, P., C.N. Madhavarao, J.R. Moffett and A.M. Namboodiri, 2008. Antipsychotic drugs increase $\mathrm{N}$-acetylaspartate and $\mathrm{N}$ acetylaspartylglutamate in SH-SY5Y human neuroblastoma cells. Neurochem, 106: 1669-1680. PMID: 18631215

Banzan, A.M. and A.O. Donoso, 1983. Enhanced prolactin release by injection of glycine in the medial Preoptic Area (mPOA) of the rat. Brain Res. Bull., 10: 9-13. PMID: 6402274

Baslow, M.H., 2000. Functions of N-acetyl-L-aspartate and $\mathrm{N}$-acetyl-L-aspartylglutamate in the vertebrate brain: Role in glial cell-specific signaling. Neurochem, 75: 453-459. PMID: 10899919

Block, W.D., M.E. Markovs and B.F. Steel, 1966 Comparison between free amino acid levels in plasma deprotienated with picric acid and with sulphosalicylic acid. Proc. Soc. Exp. Biol. Med., 122: 1089-1095. PMID: 5918130

Brooks, C.L. and C.W. Welsch, 1974. Reduction of serum prolactin in rats by 2 ergot alkaloids and 2 ergoline derivatives: a comparison Proc. Soc. Exp.Biol. Med., 146: 863-867. PMID: 4841203

Bruinvels, J. and L. Pepplinkhuizen, 1984. Impaired glycine-serine conversion and increased plasma taurine levels in episodic psychotic patients with psychedelic symptoms. J. Psychiat. Res., 18: 307-318. PMID: 6436485
Buchanan, R.W., R. Freedman, D.C. Javitt, A. AbiDargham and J.A. Lieberman, 2007. Recent advances in the development of novel pharmacological agents for the treatment of cognitive impairments in schizophrenia. Schizophr. Bull., 33: 1120-1130. PMID: 17641146

Calne, D.B., L.E. Claveria and J.L. Reid, 1975. Hypothermic action of bromocriptine. Br. J. Pharmacol., 54: 123-124. PMID: PMC1666388

Cotman, C.W., D.T. Monaghan and O.P. Ottersen, 1987. Anatomical organization of excitatory amino acid receptors and their pathways. J. Trends Neurosci., 10: 273-280. DOI: 10.1016/01662236(87)90172-X

Costa, J., E. Khaled, G. Sramek, W. Jr. Bunney and S.G. Potkin, 1990. An open trial of glycine as an adjustment to neuroleptics in chronic treatmentrefractory schizophrenics. J. Clin. Psychopharmacol., 10: 71-72. PMID: 2307738.

Coyle, J.T. and G. Tsai, 2004. The NMDA receptor glycine modulatory site: A therapeutic target for improving cognition and reducing negative symptoms in schizophrenia. Psychopharmacology, 174: 32-38. PMID: 15205876

Creese, I., D.R. Sibley and S.E. Leff, 1984. Agonist interactions with dopamine receptors: Focus on radioligand-binding studies. Fed Proc., 43: 2779-2784. PMID: 6383871

Crosignani, P.G. and C. Ferrari, 1990. Dopaminergic treatments for hyperprolactinaemia. Baillieres Clin. Obstet. Gynaecol., 4: 441-455. PMID: 1980863

Curran, C., N. Byrappa and A. Mcbride, 2004. Stimulant psychosis: Systematic review. Br. J. Psychiat., 185: 196-204. DOI: 10.1192/bjp.185.3.196

DeLisi, L.E., 2008. The concept of progressive brain change in schizophrenia: implications for understanding schizophrenia. Schizophr. Bull., 34: 312-321. DOI: $10.1093 / \mathrm{schbul} / \mathrm{sbm} 164$

Di Giovanni, M., E. Topo, A. Santillo, A. D’Aniello and G.D. Chieffi Baccari, 2010. Aspartate binding sites in rat Harderian gland. Amino Acids, 38: 229235. PMID: 19153642

El Idrissi, A., J. Messing, J. Scalia and E. Trenkner, 2003. Prevention of epileptic seizures by taurine. Adv. Exp. Med. Biol., 526: 515-525. PMID: 12908638

Goff, D.C. and J.T. Coyle, 2001. The emerging role of glutamate in the pathophysiology and treatment of schizophrenia. Am. J. Psychiat., 158: 1367-1377. PMID: 11532718 
Ho, K.Y. and M.O. Thorner, 1988. Therapeutic applications of bromocriptine in endocrine and neurological diseases. Drugs, 36: 67-82. PMID: 3063495

Javitt, D.C., 2002. Glycine modulators in schizophrenia. Curr. Opin. Investig. Drugs, 3: 1067-1072. PMID: 12186269

Johnson, A.M., D.M. Loew and J.M. Vigouret, 1976. Stimulant properties of bromocriptine on central dopamine receptors in comparison to apomorphine (+)-amphetamine and L-DOPA. Br. J. Pharmacol., 56: 59-68. PMID: 943193

Johnson, J.W. and P. Ascher, 1987. Glycine potentiates the NMDA response in cultured mouse brain neurons. Nature, 325: 529-531. PMID: 2433595

Kleckner, N.W. and R. Dingledine, 1988. Requirement for glycine in activation of NMDA-receptors expressed in Xenopus oocytes. Science, 241: 835-837. PMID: 2841759

Konradi, C. and S. Heckers, 2003. Molecular aspects of glutamate dysregulation: Implications for schizophrenia and its treatment. Pharmacol. Ther., 97: 153-179. PMID: 12559388

Levine, J., K. Panchalingam, A. Rapoport, S. Gershon, R.J. McClure and J.W. Pettegrew, 2000. Increased cerebrospinal fluid glutamine levels in depressed patients. Biol. Psychiat., 47: 586-593. PMID: 10745050

Lieberman, J.A., J.M. Kane and J. Alvir, 1987. Provocative tests with psychostimulant drugs in schizophrenia. Psychopharmacology, 91: 415-433. DOI: $10.1007 / \mathrm{BF} 00216006$

Maguire, G.A., 2002. Comprehensive understanding of schizophrenia and its treatment. Am. J. Health Syst. Pharm., 59: S4-11. PMID: 12227084

Maj, J., L. Gancarczyk and A. Rawlów, 1977. The influence of bromocriptine on serotonin neurons. Neural Transm., 41: 253-264. PMID: 925686

Meister, A., 1973. On the enzymology of amino acid transport. Science, 180: 33-39. PMID: 4144403

Millan, M.J., 2002. N-methyl-D-aspartate receptorcoupled glycineB receptors in the pathogenesis and treatment of schizophrenia: A critical review. Drug Targets CNS. Neurol. Disord., 1: 191-213. PMID: 12769627
Nowak, L., P.Bregestovski, P. Ascher, A. Herberterbert and A. Prochiantz, 1984. Magnesium gates glutamate activated channels in mouse central neurons. Nature, 397: 462-465. PMID: 6320006

Perry, T.L., P.J. Bratty, S. Hansen, J. Kennedy, N. Urquhart and C.L. Dolman, 1975. Hereditary mental depression and Parkinsonism with taurine deficiency. Arch. Neurol., 32: 108-113. PMID: 1122173

Scheibel, J., T. Elsasser and J.G. Ondo, 1980. Stimulation of prolactin secretion by taurine, a neurally depressant amino acid. Neuroendocrinology, 30: 350-354. PMID: 7383274

Shim, S.S., M.D. Hammonds and B.S. Kee, 2008. Potentiation of the NMDA receptor in the treatment of schizophrenia: Focused on the glycine site. Eur. Arch. Psychiat. Clin. Neurosci., 258: 16-27. PMID: 17901997

Sokal, R.R. and F.J. Rholf, 1981. Biometry: The Principles and Practice of Statistics in Biological Research. 2nd Edn., Freeman, WH., San Francisco, ISBN: 0-412-27630-5, pp: 128-175.

Thorner, M.O., E.W. Fluckiger and C.B. Calne, 1980. Bromocriptine: A Clinical and Pharmacological Review, Raven Press, New York, ISBN: 0890044198, pp: 42.

Tsai, G.E., P. Yang, Y.C. Chang and M.Y. Chong, 2006. D-alanine added to antipsychotics for the treatment of schizophrenia. Biol. Psychiat., 59: 230-234. PMID: 16154544

Vance, M.L., W.S Evans and M.O. Thorner, 1984. Drugs five years later: Bromocriptine. Ann. Int. Med., 100: 78-91. PMID: 6229205

Vohra, B.P. and X. Hui, 2000. Improvement of impaired memory in mice by taurine. Neural Plast., 7: 245-259. PMID: 11486485

Voog, L. and T. Eriksson, 1992. Relationship between plasma and brain large neutral amino acids in rats fed diets with different compositions at different times of the day. Neurochem, 59: 1868-1874. PMID: 1402929 